\title{
ResearchOnline@JCU
}

This is the Accepted Version of a paper published in the Journal: Construction and Building Materials

Yin, Shi, Tuladhar, Rabin, Riella, Jacob, Chung, David, Collister, Tony, Combe, Mark, and Sivakugan, Sivakugan (2016) Comparative evaluation of virgin and recycled polypropylene fibre reinforced concrete. Construction and Building Materials, 114 (1). pp. 134-141.

http://dx.doi.org/10.1016/j.conbuildmat.2016.03.162

(C) 2015. This manuscript version is made available under the CC-BY-NC-ND 4.0 license http://creativecommons.org/licenses/by-nc-nd/4.0/

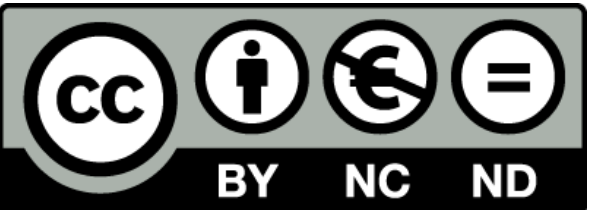


Construction \& Building Materials

Elsevier Editorial system(tm) for

Manuscript Draft

Manuscript Number: CONBUILDMAT-D-15-02167R1

Title: Comparative evaluation of virgin and recycled polypropylene fibre reinforced concrete

Article Type: Research Paper

Keywords: Recycled polypropylene fibre; fibre reinforced concrete; mechanical properties; post-cracking performance

Corresponding Author: Dr. Rabin Tuladhar,

Corresponding Author's Institution: James Cook University

First Author: Shi YIN

Order of Authors: Shi YIN; Rabin Tuladhar; Jacob Riella; David Chung; Tony Collister; Mark Combe; Nagaratnam Sivakugan

Abstract: Use of macro recycled plastic fibres in reinforcing concrete footpaths and precast panels offers significant economic and environmental benefits over traditionally used virgin plastic fibres or steel fibre and mesh. However, wide adoption of recycled plastic fibres by the construction industries has not yet been seen due to limited data available on their durability, mechanical properties and performance in concrete. This paper reports the findings from a laboratory study on the alkaline resistance and performance of recycled polypropylene (PP) fibres in $25 \mathrm{MPa}$ and $40 \mathrm{MPa}$ concrete, used for footpaths and precast panels, respectively. The recycled PP fibre was found to have lower tensile strength but higher Young's modulus than those of virgin PP fibre. The recycled PP fibre was proven to have very good alkaline resistance in the concrete and other alkaline environments. The recycled PP fibre showed excellent post-cracking performance in concrete, bringing in significant ductility. In the $40 \mathrm{MPa}$ concrete the effectiveness of reinforcement of PP fibres depended on their Young's modulus and tensile strength in the crack mouth opening displacement (CMOD) test. Therefore, the recycled PP fibre produced similar or slightly lower reinforcement than that of virgin PP fibre. In the $25 \mathrm{MPa}$ concrete, the Young's modulus of fibres was more effective on their reinforcement than the tensile strength, thus the recycled PP fibre produced better reinforcement than that of virgin PP fibre. 


\section{Comparative evaluation of virgin and recycled polypropylene fibre}

\section{2 reinforced concrete}

3 Shi Yin ${ }^{1}$, Rabin Tuladhar ${ }^{1 *}$, Jacob Riella ${ }^{1}$, David Chung ${ }^{1}$, Tony Collister ${ }^{2}$, Mark Combe ${ }^{2}$, Nagaratnam

$4 \quad$ Sivakugan $^{1}$

$5 \quad{ }^{1}$ College of Science, Technology \& Engineering, James Cook University, QLD 4811, Australia

$6 \quad{ }^{2}$ Fibercon, QLD 4051, Australia

$7 \quad$ *Corresponding author: Rabin Tuladhar (rabin.tuladhar@icu.edu.au)

8

9 Abstract

Use of macro recycled plastic fibres in reinforcing concrete footpaths and precast panels offers significant economic and environmental benefits over traditionally used virgin plastic fibres or steel fibre and mesh. However, wide adoption of recycled plastic fibres by the construction industries has not yet been seen due to limited data available on their durability, mechanical properties and performance in concrete. This paper reports the findings from a laboratory study on the alkaline resistance and performance of recycled polypropylene (PP) fibres in $25 \mathrm{MPa}$ and $40 \mathrm{MPa}$ concrete, used for footpaths and precast panels, respectively. The recycled PP fibre was found to have lower tensile strength but higher Young's modulus than those of virgin PP fibre. The recycled PP fibre was proven to have very good alkaline resistance in the concrete and other alkaline environments. The recycled PP fibre showed excellent post-cracking performance in concrete, bringing in significant ductility. In the $40 \mathrm{MPa}$ concrete the effectiveness of reinforcement of PP fibres depended on their Young's modulus and tensile strength in the crack mouth opening displacement (CMOD) test. Therefore, the recycled PP fibre produced similar or slightly lower reinforcement than that of virgin PP fibre. In the 25 MPa concrete, the Young's modulus of fibres was more effective on their 
reinforcement than the tensile strength, thus the recycled PP fibre produced better reinforcement than that of virgin PP fibre.

Keywords: Recycled polypropylene fibre, fibre reinforced concrete, mechanical properties, postcracking performance

\section{Introduction}

Use of steel reinforcing mesh to reinforce concrete pavements requires labour time for laying, cutting and tying of steel mesh before concrete is poured [1]. Moreover, steel is vulnerable to corrosion and hence, reinforced concrete members if not designed and constructed properly can deteriorate due to corrosion of steel. Production of steel mesh and fibre also produces significant carbon footprint. For example, production process of steel mesh typically required to reinforce $100 \mathrm{~m}^{2}$ of concrete footpath emits about $1250 \mathrm{~kg}$ of carbon dioxide [2]. Macro plastic fibers, such as polypropylene (PP) [3], high-density polyethylene (HDPE) [4] and polyethylene terephthalate (PET) fibres [5], therefore, have gradually become an attractive alternative to steel mesh and fibre for construction of concrete footpaths, non-structural precast elements, and tunnels linings. Use of macro plastic fibres in concrete has multiple advantages, such as ease of construction, reduced labour time and lower time. These plastic fibres can effectively improve post-cracking performance and control dry shrinkage of concrete [6]. They normally have a tensile strength of 300-600 MPa and a Young's modulus of 4-10 GPa, and are made of virgin plastics [7].

In order to promote development of concrete industry, recycled plastic fibres have started attracting attention around the world [8]. Ochi, Okubo [1] and Fraternali, Ciancia [9] produced recycled PET fibres though a serial processes of extrusion, spinning and stretching. The recycled PET fibres produced in both their studies achieved a tensile strength of over $450 \mathrm{MPa}$. Kim, Park [10] and Kim, Yi [11] produced recycled PET fibre by melting waste PET bottles first, then pressing and rolling them 
into a roll-type sheets, before slitting the sheets into thin strands. The recycled PET fibres produced in this way had a tensile strength of more than $400 \mathrm{MPa}$ and a Young's modulus of $10 \mathrm{GPa}$. de Oliveira and Castro-Gomes [12] and Foti [5] produced recycled PET fibres by simply cutting waste PET bottles, but these fibres had limited strength. Although recycled PET fibres have recently become a focus of research, research on mechanical properties of recycled PP fibre and their effectiveness as reinforcement in concrete is very limited.

Effectiveness of the fibres in reinforcing concrete is generally assessed through the crack mouth opening displacement (CMOD) test and round determinate panel test (RDPT), which assess the postcracking performance of fibre reinforced concrete. CMOD test is suitable for determining how the fibres control the cracks, as it demonstrates the association between cracking behaviour and residual flexural strength. The CMOD test evaluates the capacity of fibres to bridge the cracks formed and redistribute the stresses [13]. RDPT is also an effective method of assessing the performance of fibre reinforced concrete. This technique is desirable because panels are subjected to a mixture of stress actions that more accurately reflect the in-situ behaviour of concrete than other laboratory based small-specimen mechanical tests. Significantly lower variability in post-cracking performance is also seen in the RDPT than other tests, consequently, energy absorption in the RDPT is considered one of the most reliable test methods of post-cracking performance assessment [14].

Durability of plastic fibres in highly alkaline cement matrix is another important factor that needs proper consideration. Brown et al. [15] exposed virgin PP fibres to an ionic environment of sodium and chloride ions created by salt water at $71^{\circ} \mathrm{C}$ and $-7^{\circ} \mathrm{C}$ for six months, tensile properties of the PP fibres remained unchanged. Elasto Plastic Concrete (EPC) Company [16] subjected virgin PP fibres to an alkaline solution simulating alkaline environment of concrete mix. They reported that the PP fibres can last up to 100 years in an alkaline environment without any reduction in strength. While it is clearly demonstrated that the long-term durability is not a problem for the virgin PP fibres, the durability of recycled PP fibres in the alkaline environment of concrete is still unknown. 
This research, therefore, assesses the alkaline resistance of recycled PP fibre in four different alkaline solutions to study degradation of the recycled PP fibre in different $\mathrm{pH}$ ranges and types. The postcracking performance of recycled PP fibre reinforced concretes was also quantified and compared with that of virgin PP fibre reinforced concretes through the CMOD test and RDPT. In this study, two volume percentages of fibres are chosen to reinforce $40 \mathrm{MPa}$ and $25 \mathrm{MPa}$ concrete, which are the standard grades of concrete used in precast panels and concrete footpaths, respectively. The effectiveness of the recycled PP fibres as reinforcement of the two different grades of concrete are assessed in this research.

\section{Materials properties}

\subsection{Recycled and virgin PP fibres}

In this study the recycled PP fibre was produced by extruding, spinning and stretching recycled PP granules, which are made of industrial PP waste (scrap off-cuts and off-specification items in the manufacturing industry that are not used by the consumer). Initial extrusion of the PP granules was carried out at $210-250^{\circ} \mathrm{C}$, spinning and stretching at $140-170^{\circ} \mathrm{C}$, then stabilisation at $110-140{ }^{\circ} \mathrm{C}$. Smooth surface fibres, $0.8-0.9 \mathrm{~mm}$ in diameter, were then produced followed by indentation on the surface using an indenting roller die to improve fiber-concrete bonding. After that, the fibre was winded, polywrapped and finally cut into a specific length. Both recycled and virgin PP fibres were produced by the same processes, thus having same geometry and dimensions ( $1.5 \mathrm{~mm}$ in width, 0.7 $\mathrm{mm}$ in thickness, and $47 \mathrm{~mm}$ in length), as shown in Fig. 1.

(Insert Fig. 1 here)

Tests on recycled and virgin PP fibres for tensile strength and Young's modulus were carried out as per ASTM D3822-07 [17]. Tensile tests were undertaken using United Calibration Corporation United STM 'Smart' Test Machine (STM-50 KN) with a $2 \mathrm{kN}$ load cell and a data acquisition software. 30 
samples of each of the fibre types were tested at room temperature of $20 \pm 2{ }^{\circ} \mathrm{C}$. Gauge length of $25.4 \mathrm{~mm}$ was used with extension speed set at $60 \%$ of the gauge length $/ \mathrm{min}(15.24 \mathrm{~mm} / \mathrm{min})$ for all the tests.

A brittle mode of failure can be seen in both types of fibres (Fig. 2), with a short elastic phase of steep slope and a progression of sharply rising stress until fracture. Averages of the tensile strength and Young's modulus are shown in Table 1 as well as the elongation at break and their standard deviations. As can be seen, the recycled PP fibre shows lower tensile strength (284.1 MPa) but much higher Young's modulus (4582 MPa) than those of virgin PP fibre. It is noteworthy that the recycle PP fibre is not featured to have higher Young's modulus than that of virgin PP fibre. The tensile properties of fibres mainly depend on the material properties and processing conditions. Our previous research [18] has shown that the recycled PP fibre has lower molecular weight and shorter molecular chains than those of virgin PP fibre. Under the same processing conditions, the shorter molecular chains make the recycled PP fibre easier to be crystallised, thus producing higher Young's modulus. The shorter molecular chains of recycle PP fibre have less molecular entanglement and hence, producing lower tensile strength under the same processing conditions with the virgin PP fibre. However, if the processing conditions or methods are changed, the properties of fibres are changed, which is out of the scope of this paper.

\section{(Insert Fig. 2 and Table 1 here)}

\subsection{Concrete mix design}

Based on industry practise, standard mix designs for $40 \mathrm{MPa}$ and $25 \mathrm{MPa}$ concrete were used in this study (as shown in Table 2). For the $40 \mathrm{MPa}$ concrete mix design, $0.67 \%$ in volume of PP fibres (6 $\mathrm{kg} / \mathrm{m}^{3}$ ) was mixed with concrete, which is normal dosage of PP fibres for $40 \mathrm{MPa}$ concrete construction of precast panels. For the $25 \mathrm{MPa}$ concrete, $0.45 \%$ in volume of PP fibres $\left(4 \mathrm{~kg} / \mathrm{m}^{3}\right)$ was mixed. This design is commonly used to construct concrete footpaths. Delivery of concrete was 
carried out in a standard concrete truck from a Holcim Australia Pty. Ltd. batch plant and without PP fibres. Average slump was $60 \mathrm{~mm}$ for the $40 \mathrm{MPa}$ concrete and $100 \mathrm{~mm}$ for the $25 \mathrm{MPa}$ concrete, based on AS 1012.3.1-2014 [19]. PP fibres were then mixed with concrete in a drum mixer before casting specimens. Fibres were gradually added to avoid clumping and ensure good dispersion. Based on AS 1012.8.1:2014 [20], concrete beams, cylinders and round panel slabs were removed from the moulds after 24 hours. All specimens were then cured in water at $23 \pm 2{ }^{\circ} \mathrm{C}$ for 28 days.

\section{Alkali resistance of the recycled PP fibre}

Alkali resistance test was conducted to study possible degradation of the recycled PP fibre in concrete alkaline environment. The recycled PP fibre was immersed into a Lawrence solution [0.48 $\left.\mathrm{g} / \mathrm{l} \mathrm{Ca}(\mathrm{OH})_{2}+3.45 \mathrm{~g} / \mathrm{I} \mathrm{KOH}+0.88 \mathrm{~g} / \mathrm{l} \mathrm{NaOH}, \mathrm{pH}=12.9\right]$, which is considered to simulate pore water composition of a fully hydrated cement paste [21]. The recycled PP fibre was also immersed in three other alkaline solutions with $\mathrm{pH}$ value ranging from 12.3 to 13.5 to study degradation of the fibre in different $\mathrm{pH}$ ranges and types. These three alkaline solutions used were $\mathrm{Ca}(\mathrm{OH})_{2}$ saturated solution $(\mathrm{pH}=12.3), 0.068 \mathrm{~mol} / \mathrm{I} \mathrm{KOH}$ solution $(\mathrm{pH}=12.83)$, and $0.28 \mathrm{~mol} / \mathrm{I} \mathrm{NaOH}$ solution $(\mathrm{pH}=13.45)$. The recycled PP fibre was immersed into these four solutions for 28 days at ambient temperature. The tensile strength and Young's modulus of recycled PP fibre were measured before and after immersion.

As can be seen from Fig. 3, all the curves representing fibre immersion in the alkaline solutions nearly overlap with the curves of fibre without immersion, indicating that the recycled PP fibre has outstanding alkali resistance in the various alkaline environments. However, there still are some minor changes on the mechanical properties after immersion. As shown in Table 3, the $\mathrm{NaOH}$ solution slightly embrittles the recycled PP fibre, thus decreasing the tensile strength and increasing the Young's modulus of fibre, due to its higher $\mathrm{pH}$ value. The $\mathrm{KOH}$ solution slightly decreases the tensile strength of fibre. However, there is nearly no change after immersing the fibre in the 

shows good alkali resistance in all the alkaline environments tested.

\section{Compressive strength of concrete}

Compressive strength tests were performed according to AS 1012.9:2014 [22] on the PP fibre

reinforced concrete specimens. Testing was done on the $100 \mathrm{~mm}$ diameter by $200 \mathrm{~mm}$ length fibre concrete cylinders after they had aged for 28 days. Cylindrical specimens were tested by axial loading until failure by using a universal testing machine with a maximum load capacity of $2000 \mathrm{kN}$. Results of compressive strength for concrete comprising each of the fibre varieties were based on four specimen's average value.

The PP fibre reinforced concrete cylinder's compressive strength is shown in Fig. 4. This shows no significant effect on compressive strength after addition of fibres. Concrete with low dosage of PP fibres $\left(4\right.$ and $6 \mathrm{~kg} / \mathrm{m}^{3}$ ) have no obvious effect on compressive strength, which has also been shown by other research [23]. However, larger fibre doses (i.e. 13 to $18 \mathrm{~kg} / \mathrm{m}^{3}$ ) can lead to improper distribution resulting in balling of fibres and air pockets, which adversely affects the compressive strength of concrete [1]. Moreover, recycled and virgin PP fibre reinforced concrete cylinders had large single crack. In other words, the fibre concretes displayed a more ductile mode of failure.

\section{Residual flexural tensile strength with CMOD}

To study post-cracking performance of the concrete beams reinforced with PP fibres, crack mouth opening displacement (CMOD) tests were conducted according to BS EN 14651-2005+A1-2007 [24]. 

notch was cut at mid-span of each beam (Fig. 5). Each notched beam was loaded using a $500 \mathrm{kN}$ hydraulic testing machine on a three-point loading setup. The CMOD measurement was obtained by installing two clip gauges at the notch centre and the averaged CMOD values were documented. The clip gauges that were attached to the knife edges glued to the underside of beam were connected to a data acquisition system. All the tests were displacement controlled to accomplish a constant rate of $0.05 \mathrm{~mm} / \mathrm{min} \mathrm{CMOD}$ and were undertaken at the facilities of K\&H Geotechnical Services Pty. Ltd., Australia. Three samples for each fibre and concrete type were tested, along with one plain concrete beam was tested as a control specimen.

Fig. 6.a shows load-CMOD curves of $0.67 \%$ PP fibres reinforced concrete beams of $40 \mathrm{MPa}$ compressive strength. The peak loads reached for all the recycled and virgin PP fibre reinforced concrete beams were approximately $14.5 \mathrm{kN}$, followed by a sharp drop associated with the CMOD range of $0.05 \mathrm{~mm}$ to $0.5 \mathrm{~mm}$. Further, the CMOD from $0.5 \mathrm{~mm}$ to $3 \mathrm{~mm}$ was associated with increased loads, which then remained flat at $4-8 \mathrm{kN}$ on further loading. However, the load dropped to zero for the plain concrete beam after the peak load was attained.

Fig. 6.b exhibits load-CMOD curves of $0.45 \%$ PP fibre reinforced concrete beams of target strength $25 \mathrm{MPa}$. The peak loads for all the beams were approximately around $12.5 \mathrm{kN}$, before a sudden drop. The loads then just kept flat at 2-5 kN until failure, which is different from the increasing load at the CMOD from $0.5 \mathrm{~mm}$ to $3 \mathrm{~mm}$ in the Fig. 6.a. This is because the $0.45 \%$ PP fibre reinforced $25 \mathrm{MPa}$ concrete beams have lower fibre dosage and concrete strength than those of $0.67 \%$ PP fibre reinforced MPa concretes. As expected, the load dropped to $0 \mathrm{kN}$ soon after the peak load for the plain concrete beam. Fig. 6 .a and Fig. $6 . \mathrm{b}$ confirm the outstanding post-cracking performance of the recycled and virgin PP fibre reinforced concrete beams. 
Fig. 6.c compares the reinforcement of $0.45 \%$ recycled PP fibre in 25 and $40 \mathrm{MPa}$ concrete. After the peak load and the following sharp drop, the loads of fibre reinforced $40 \mathrm{MPa}$ concrete slightly increased and then kept flat, and showed slightly better post-cracking performance than that of the fibres in $25 \mathrm{MPa}$ concrete. This shows that with the increase in compressive strength of concrete the performance of PP fibres is more pronounced.

(Insert Fig. 6 here)

Fig. 7 compares flexural tensile strength at the peak load (i.e. Limit of Proportionality, LOP) for the recycled and virgin PP fibre reinforced concrete beams compared to the plain concrete beams. As can be seen, for both $40 \mathrm{MPa}$ and $25 \mathrm{MPa}$ concrete beams, the recycled PP fibre reinforced concrete beams have comparable LOP to that of virgin PP fibre reinforced concrete. Compared to $40 \mathrm{MPa}$ and $25 \mathrm{MPa}$ plain concrete beams, the LOP does not have obvious change after adding the PP fibres. This is because the LOP reflects the flexural tensile strength of uncracked concrete beams, and thus it mainly depends on the concrete material not the fibres. Only after the beams crack, will the fibre hold the load and contribute to the residual flexural tensile strength. Therefore, the plain concrete theoretically has equivalent LOP with the fibre reinforced concrete, and it is normal if the plain concrete has slightly higher or lower LOP due to the micro defects or cracks of concrete.

(Insert Fig. 7 here)

Fig. 8 compares the residual flexural tensile strength of PP fibres reinforced concrete beams at $\mathrm{CMOD}_{1}, \mathrm{CMOD}_{2}, \mathrm{CMOD}_{3}$ and $\mathrm{CMOD}_{4}$. As can be seen, for the $40 \mathrm{MPa}$ concrete, the recycled PP fibre reinforced concretes show comparable or only slightly lower residual flexural strength than that of concretes reinforced by the virgin PP fibre. Moreover, from Fig. 8.a to Fig. 8.d, with the increase of CMOD, the residual flexural tensile strength of the fibre reinforced $40 \mathrm{MPa}$ concrete beam increases from 1.5 MPa to 2.0 MPa. On the other hand, for the $0.45 \%$ fibre reinforced $25 \mathrm{MPa}$ concrete, the average residual flexural tensile strength of recycled PP reinforced concretes is slightly higher that of 
virgin PP fibre reinforced concretes. Furthermore, the residual flexural tensile strength just keeps stable around 1.0 MPa from $\mathrm{CMOD}_{1}$ to $\mathrm{CMOD}_{4}$, instead of increasing.

It is noteworthy that the CMOD test has some variability even in the same batch of specimens due to multiple reasons. Since the beam specimens are notched and subjected to mid-point loading in the test, crack initiates at the notch-tip and propagates along the notch plane and hence, deformation is always localised at the notch-plane and the rest of the beam does not undergo significant inelastic deformations. Therefore, the results of the CMOD tests highly depend on the dispersion, amount and orientation of the PP fibres only on the notch-plane with a small area of $150 \mathrm{~mm} \times 125 \mathrm{~mm}$. Moreover, the tensile properties of individual PP fibre are also different, which can be reflected by the deviation in Table 1. Therefore, the variability of dispersion, amount, orientation and tensile properties of PP fibres on the notch-plane of concrete beam specimens lead to the variability of results in Fig. 8.

Fig. 9 shows fracture faces of the fibre reinforced concrete beams. Fig. 9.a and Fig. 9.b represent the fracture faces of recycled and virgin PP fibre reinforced $40 \mathrm{MPa}$ concrete beams, respectively. As can be seen, the amount of fibre breakage was higher than that of fibre pull-out, which indicates good bonding of fibres with the $40 \mathrm{MPa}$ concrete matrix. The tensile capacity of the broken PP fibres was fully realised, thus producing good reinforcement. As the ultimate tensile capacity was reached in the broken fibres, the performance of fibres depended on both their tensile strength and Young's modulus. From Table 1, it can be seen that the recycled PP fibre has higher Young's modulus but lower tensile strength than the virgin PP fibre. Although the lower tensile strength made the fibre easier to be broken, the higher Young's modulus improved the performance of recycled PP fibre in concrete before breaking. Consequently, the recycled PP fibre produced similar or slightly lower performance than that of the virgin PP fibre in $40 \mathrm{MPa}$ concrete beams. Moreover, the failure modes of recycled and virgin PP fibre are different. In the case of recycled PP fibre reinforced concrete (Fig. 

stretched into massive split micro fibres, showing a more ductile failure (Fig. 9.b). This is because the recycled PP fibre has very low elongation at break (6.2\%), while the virgin PP fibre is more ductile and has much higher elongation at break at $12.6 \%$.

The fracture faces of $25 \mathrm{MPa}$ concrete beams are different with those of $40 \mathrm{MPa}$ concretes as shown in Fig. 9.c and Fig. 9.d. In the low-strength concrete (25 MPa), nearly all the fibres were pulled out without being broken, indicating that the low-strength concrete has a poor bonding with the fibres. Because of the poor bonding, majority of the fibres remained unbroken, and thus their full tensile capacity was not realised. Therefore, the Young's modulus of fibres is more effective on their reinforcement than the tensile strength. The recycled PP fibre has higher Young's modulus than that of virgin PP fibre, thus showing better reinforcement in the CMOD tests.

\section{Flexural strength and toughness from RDPT}

The RDPT samples were tested in flexure based on the ASTM C1550-12 [25] (Fig. 10). All of the tested round panels were $800 \mathrm{~mm}$ in diameter with a thickness of $75 \mathrm{~mm}$. The specimens were mounted on three symmetrically arranged hinged supports, and tested using a central point load. Load was applied using a $250 \mathrm{kN}$ capacity hydraulic universal testing machine and the three pivoted supports ensured that load distribution was always determinate. As specified in the standard, maximum central displacement of $45.0 \mathrm{~mm}$ was achieved after application of displacement at a rate of $4.0 \mathrm{~mm} / \mathrm{min}$. A displacement transducer, which was placed under the centre of the specimen, was used to record the deflection. The tests were carried out at K\&H Geotechnical Services Pty. Ltd., Australia. 
Fig. 11 shows the energy absorption and load results of the RDPT with the increase of deflection. As can be seen, all the fibre reinforced concrete panels reached a peak load at the deflection of $1 \mathrm{~mm}$, before a sudden drop to 5-8 kN. The loads then kept flat until deflection of $10 \mathrm{~mm}$, before a stable downward trend to about $1.5 \mathrm{kN}$.

The energy absorption is the area under the load curves, which reflects the performance of fibre reinforcement in dissipating energy. As can be seen from Fig. 11.a, the recycled PP fibre had slightly lower energy absorption than that of the virgin PP fibre, indicating that the recycled PP fibre produced slightly lower post-cracking reinforcement than that of virgin PP fibre. This result is consistent with CMOD results. The reinforcement of PP fibres in $40 \mathrm{MPa}$ concrete depends on both their Young's modulus and tensile strength. Although the recycled PP fibre had lower tensile strength, its higher Young's modulus improved its reinforcing effects. Consequently, a comparable reinforcement with virgin PP fibre was produced by the recycled PP fibre in the $40 \mathrm{MPa}$ concrete.

For the $25 \mathrm{MPa}$ concrete, the recycled PP fibre produced higher post-cracking reinforcement than that of virgin PP fibre (Fig. 11.b). As discussed before, the PP fibres have poor bonding with concrete matrix in the low-strength concrete and hence, the Young's modulus is more effective on the reinforcement. The recycled PP fibre has higher Young's modulus, thus producing better reinforcement.

(Insert Figure 11 here)

\section{Conclusion}

Significant environmental and economic benefits can be obtained through the use of macro recycled plastic fibres over virgin plastic fibres, or the traditionally used steel mesh and fibre, for reinforcing concrete footpaths and precast panels. However, the wide adoption of recycled plastic fibres has not yet been adopted due to limited research focusing on their durability, performance in concrete, and 
mechanical properties. This research studied the alkaline resistance and performance of recycled PP fibres in concrete for footpaths and precast panels.

The alkali resistance of recycled PP fibre was tested by immersing the fibre in four different alkaline solutions for 28 days. The comparison of tensile strength and Young's modulus of fibres before and after immersion showed that the recycled PP fibre did not degrade in the alkaline concrete environment.

The addition of recycled PP fibre at low dosage rate $\left(4\right.$ and $\left.6 \mathrm{~kg} / \mathrm{m}^{3}\right)$ did not affect compressive strength of concrete, however, it significantly improved the residual flexural tensile strength of concrete. The CMOD tests on $40 \mathrm{MPa}$ concrete beams with $6 \mathrm{~kg} / \mathrm{m}^{3} \mathrm{PP}$ fibres (normally used for precast concrete elements) showed that most of the fibres were broken instead of being pulled out at the failure load. This inferred good bonding of fibres with concrete, hence the performance of PP fibres was influenced by both Young's modulus and tensile strength of fibres. The recycled fibre had higher Young's modulus but lower tensile strength than those of virgin PP fibre. Consequently, recycled PP fibre showed slightly lower performance than that of virgin PP fibre in the $40 \mathrm{MPa}$ concrete. In the $25 \mathrm{MPa}$ concrete, majority of fibres were being pulled out instead of breaking. As the fibres did not reach their ultimate tensile strength, their Young's modulus was more influential. The recycled PP fibre had higher Young's modulus and hence, performed better than virgin PP fibre in the $25 \mathrm{MPa}$ concrete.

The results of RDPT proved that the recycled PP fibre produced comparable post-cracking performance with that of the virgin PP fibre in the $40 \mathrm{MPa}$ concrete, and better performance than that of virgin PP fibre in the $25 \mathrm{MPa}$ concrete. This study proved that the post-cracking performance of recycled PP fibre reinforced concrete is in par with the virgin PP fibre reinforced concrete. precast panels. 
313 [1] Ochi T, Okubo S, Fukui K. Development of recycled PET fiber and its application as concretereinforcing fiber. Cement Concrete Comp. 2007;29(6):448-55.

[2] Yin S, Tuladhar R, Shi F, Combe M, Collister T, Sivakugan N. Use of macro plastic fibres in concrete: A review. Constr Build Mater. 2015;93(15):180-8.

[3] Yin S, Tuladhar R, Collister T, Combe M, Sivakugan N. Mechanical Properties and Post-crack Behaviours of Recycled PP Fibre Reinforced Concrete. In: Proceedings of the 27th Biennial National Conference of the Concrete Institute of Australia, Construction Innovations, Research into Practice, pp 414-421 From: 27th International Conference Concrete 2015, 30 August-2 September, 2015, Melbourne, Australia. 2015.

[4] Silva ER, Coelho JFJ, Bordado JC. Strength improvement of mortar composites reinforced with newly hybrid-blended fibres: Influence of fibres geometry and morphology. Constr Build Mater. 2013;40:473-80.

[5] Foti D. Preliminary analysis of concrete reinforced with waste bottles PET fibers. Constr Build Mater. 2011;25(4):1906-15.

[6] Alani AM, Beckett D. Mechanical properties of a large scale synthetic fibre reinforced concrete ground slab. Constr Build Mater. 2013;41:335-44.

[7] Di Maida P, Radi E, Sciancalepore C, Bondioli F. Pullout behavior of polypropylene macrosynthetic fibers treated with nano-silica. Constr Build Mater. 2015;82:39-44.

[8] Fraternali F, Spadea S, Berardi VP. Effects of recycled PET fibres on the mechanical properties and seawater curing of Portland cement-based concretes. Constr Build Mater. 2014;61:293-302.

[9] Fraternali F, Ciancia V, Chechile R, Rizzano G, Feo L, Incarnato L. Experimental study of the thermo-mechanical properties of recycled PET fiber-reinforced concrete. Compos Struct. 2011;93(9):2368-74.

[10] Kim JHJ, Park CG, Lee SW, Lee SW, Won JP. Effects of the geometry of recycled PET fiber reinforcement on shrinkage cracking of cement-based composites. Compos Part B-Eng. 2008;39(3):442-50.

[11] Kim SB, Yi NH, Kim HY, Kim JHJ, Song YC. Material and structural performance evaluation of recycled PET fiber reinforced concrete. Cement Concrete Comp. 2010;32(3):232-40.

[12] de Oliveira LAP, Castro-Gomes JP. Physical and mechanical behaviour of recycled PET fibre reinforced mortar. Constr Build Mater. 2011;25(4):1712-7.

[13] Buratti N, Mazzotti C, Savoia M. Post-cracking behaviour of steel and macro-synthetic fibrereinforced concretes. Constr Build Mater. 2011;25(5):2713-22.

[14] Ciancio D, Mazzotti C, Buratti N. Evaluation of fibre-reinforced concrete fracture energy through tests on notched round determinate panels with different diameters. Constr Build Mater. 2014;52:86-95.

[15] Brown R, Shukla A, Natarajan KR. Fiber reinforcement of concrete structures. URITC PROJECT NO 536101. 2002.

[16] EPC. Advanced alkalinity testing. Elasto Plastic Concrete wwwelastoplasticcom (assessed by 10/11/2014). 2012.

[17] ASTM. ASTM D3822. Standard Test Method for Tensile Properties of Single Textile Fibers. Book of ASTM Standards Philadelphia. 2007.

[18] Yin S, Tuladhar R, Shanks RA, Collister T, Combe M, Jacob M, et al. Fiber preparation and mechanical properties of recycled polypropylene for reinforcing concrete. J Appl Polym Sci. 2015;132(16):41866.

[19] AS. AS 1012.3.1:2014 Methods of testing concrete - Determination of properties related to the consistency of concrete - Slump test. Standard Australia. 2014.

[20] AS. AS 1012.8.1:2014 Methods of testing concrete - Method for making and curing concrete Compression and indirect tensile test specimens. standard Australia. 2014. 
[21] Silva DA, Betioli AM, Gleize PJP, Roman HR, Gomez LA, Ribeiro JLD. Degradation of recycled PET fibers in Portland cement-based materials. Cement Concrete Res. 2005;35(9):1741-6. [22] AS. AS 1012.9:2014 Methods of testing concrete - Compressive strength tests - Concrete, mortar and grout specimens. Standard Australia. 2014. [23] Hasan M, Afroz M, Mahmud H. An experimental investigation on mechanical behavior of macro synthetic fibre reinforced concrete. International Journal of Civil \& Environmental Engineering IJCEEIJENS. 2011;11(03):18-23.

368 [24] EN B. BS EN 14651:2005+A1:2007 Test method for metallic fibre concrete. Measuring the flexural tensile strength (limit of proportionality (LOP), residual). 2005. [25] ASTM. ASTM C1550 - 12a Standard Test Method for Flexural Toughness of Fiber Reinforced Concrete (Using Centrally Loaded Round Panel). American Society for Testing and Materials Book of ASTM Standards. 2012. 


\section{Captions for figures and tables}

375 Fig. 1 Recycled (a) and virgin (b) PP fibres

Fig. 2 Typical stress-strain curves of PP fibres in tension

377 Fig. 3 Typical stress-strain curves of the recycled PP fibre in tension before and after immersing in the alkaline solutions

Fig. 4 Compressive strength of $0.67 \%$ fibre reinforced $40 \mathrm{MPa}$ concrete and $0.45 \%$ fibre reinforced $25 \mathrm{MPa}$ concrete cylinders

Fig. 5 Test apparatus for the CMOD test

Fig. 6 Load-CMOD curves for (a) 0.67\% PP fibre reinforced 40 MPa concrete, (b) $0.45 \%$ PP fibre reinforced $25 \mathrm{MPa}$ concrete, and (c) $0.45 \%$ recycled PP fibre reinforced $25 \mathrm{MPa}$ and $40 \mathrm{MPa}$ concrete

Fig. 7 LOP of $0.67 \%$ fibre reinforced $40 \mathrm{MPa}$ concrete and $0.45 \%$ fibre reinforced $25 \mathrm{MPa}$ concrete beams

Fig. 8 Residual flexural tensile strength of $0.67 \%$ fibre reinforced $40 \mathrm{MPa}$ concrete and $0.45 \%$ fibre 
Table 1 Mechanical properties of PP fibres

395

Table 2 Concrete mix proportions

396 Table 3 Mechanical properties of the recycled PP fibre before and after immersing in the alkaline

397 solutions

398 
Table 1 Mechanical properties of PP fibres

\begin{tabular}{ccccccc}
\hline & \multicolumn{2}{c}{$\begin{array}{c}\text { Tensile strength } \\
(\mathrm{MPa})\end{array}$} & $\begin{array}{c}\text { Young's Modulus } \\
(\mathrm{MPa})\end{array}$ & \multicolumn{2}{c}{$\begin{array}{c}\text { Elongation at break } \\
\text { (\%) }\end{array}$} \\
\cline { 2 - 7 } PP compositions & Average & $\begin{array}{c}\text { Standard } \\
\text { deviation }\end{array}$ & Average & $\begin{array}{c}\text { Standard } \\
\text { deviation }\end{array}$ & Average & $\begin{array}{c}\text { Standard } \\
\text { deviation }\end{array}$ \\
\hline Virgin PP Fibre & 356.4 & 30.6 & 3129 & 564 & 12.6 & 2.8 \\
Recycled PP Fibre & 284.1 & 21.0 & 4582 & 1661 & 6.2 & 2.2 \\
\hline
\end{tabular}


Table 2 Concrete mix proportions

\begin{tabular}{lcc}
\hline \multicolumn{1}{c}{ Material } & $40 \mathrm{MPa}$ Concrete & 25 MPa Concrete \\
\hline $0.6-4.75 \mathrm{~mm}$ Coarse sand $\left(\mathrm{kg} / \mathrm{m}^{3}\right)$ & 350 & 410 \\
6.7-9.5 mm Concrete aggregate $\left(\mathrm{kg} / \mathrm{m}^{3}\right)$ & 950 & 260 \\
$0.3-5 \mathrm{~mm}$ Crusher dust $\left(\mathrm{kg} / \mathrm{m}^{3}\right)$ & 220 & 200 \\
$0.075-0.3 \mathrm{~mm}$ Fine sand $\left(\mathrm{kg} / \mathrm{m}^{3}\right)$ & 290 & 350 \\
$9.5-19 \mathrm{~mm}$ Concrete aggregate $\left(\mathrm{kg} / \mathrm{m}^{3}\right)$ & - & 690 \\
Fly ash $\left(\mathrm{kg} / \mathrm{m}^{3}\right)$ & 130 & 134 \\
Cement $\left(\mathrm{kg} / \mathrm{m}^{3}\right)$ & 256 & 186 \\
Polyheed 8190 admixture $(\mathrm{ml} / 100 \mathrm{~kg}$ & 337 & 281 \\
cementitious materials) & & 22 \\
Air entrapment admixture $(\mathrm{ml} / 100 \mathrm{~kg}$ & - & 116 \\
cementitious materials) & 105 & 4 \\
Water $\left(\mathrm{l} / \mathrm{m}^{3}\right)$ & 6 & \\
PP fibre $\left(\mathrm{kg} / \mathrm{m}^{3}\right)$ & & \\
\hline
\end{tabular}


Table 3 Mechanical properties of the recycled PP fibre before and after immersing in the alkaline solutions

\begin{tabular}{ccccccc}
\hline & Tensile strength (MPa) & \multicolumn{2}{c}{ Young's Modulus (MPa) } & \multicolumn{2}{c}{ Elongation at break (\%) } \\
\cline { 2 - 7 } & Average & $\begin{array}{c}\text { Standard } \\
\text { deviation }\end{array}$ & Average & $\begin{array}{r}\text { Standard } \\
\text { deviation }\end{array}$ & Average & $\begin{array}{r}\text { Standard } \\
\text { deviation }\end{array}$ \\
\hline $\begin{array}{c}\text { Without } \\
\text { immersion } \\
\text { Lawrence }\end{array}$ & 284.1 & 33.7 & 4582 & 268.9 & 6.2 & 2.3 \\
$\begin{array}{c}\text { solution } \\
\mathrm{Ca}(\mathrm{OH})_{2}\end{array}$ & 284.7 & 22.7 & 4592 & 153.4 & 6.2 & 0.9 \\
$\begin{array}{c}\text { solution } \\
\mathrm{KOH}\end{array}$ & 273.4 & 34.7 & 4482 & 380.2 & 6.1 & 1.7 \\
$\begin{array}{c}\text { solution } \\
\mathrm{NaOH} \\
\text { solution }\end{array}$ & 261.9 & 17.4 & 4516 & 114.5 & 5.8 & 1.0 \\
\hline
\end{tabular}


Click here to download high resolution image

(a)

(b)

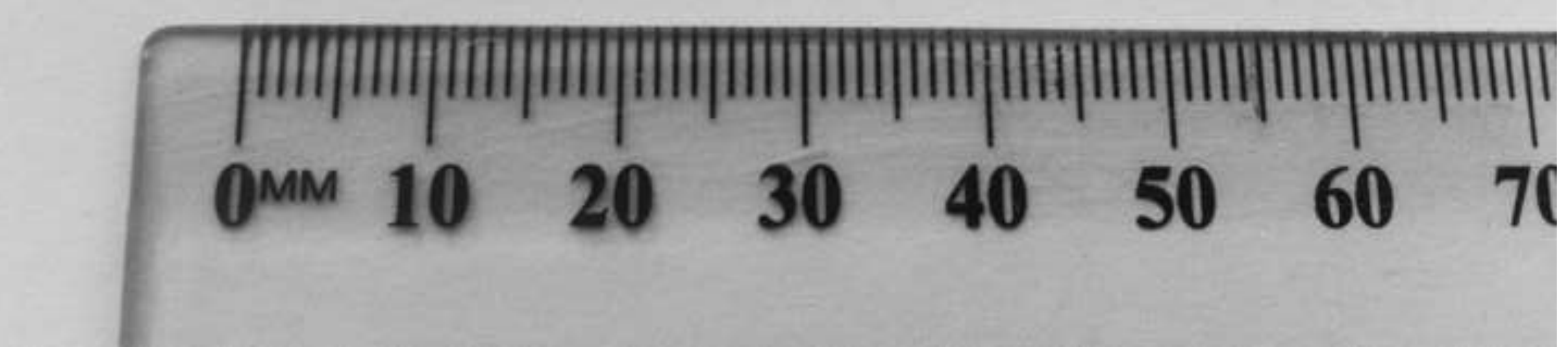




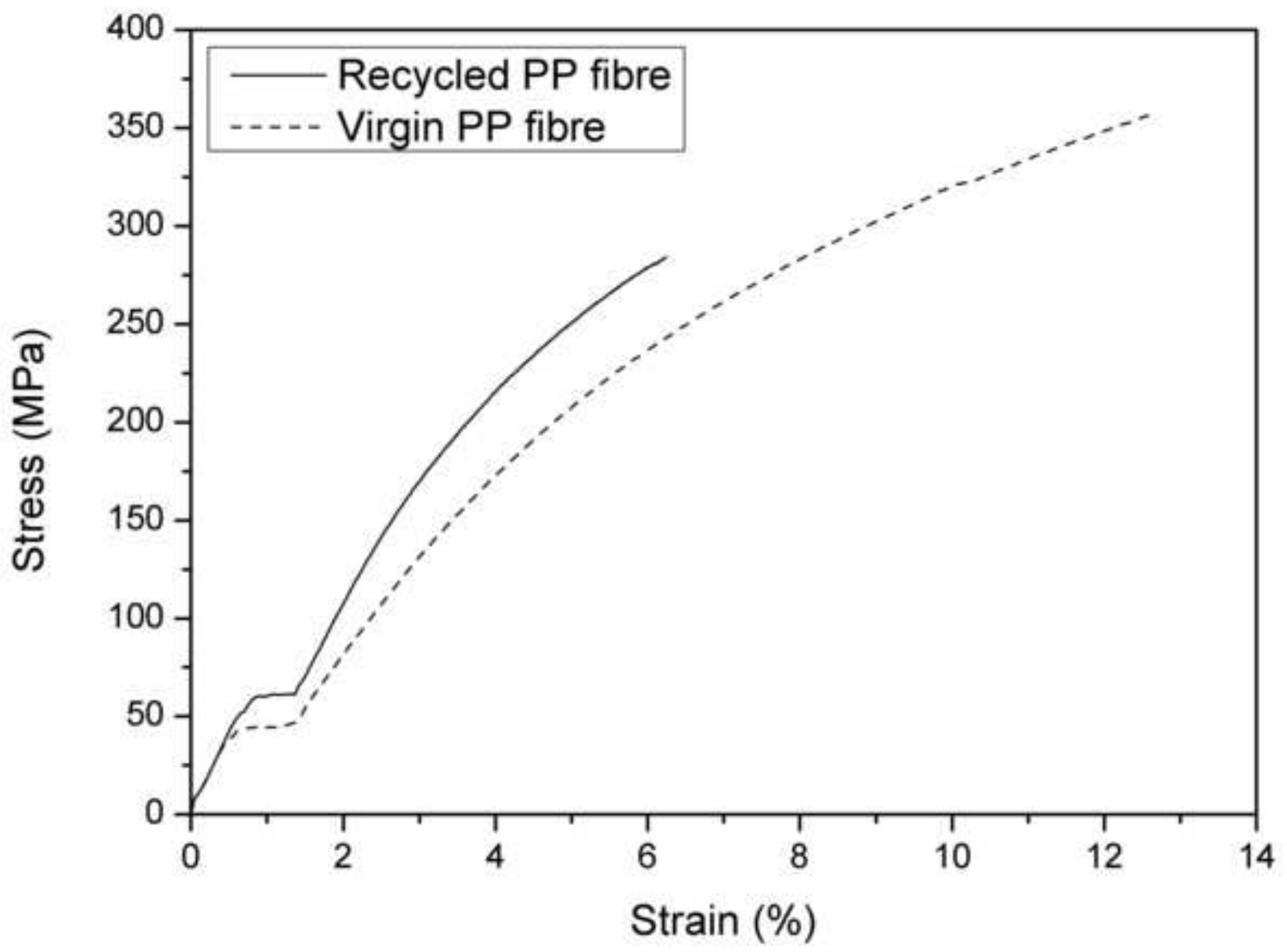




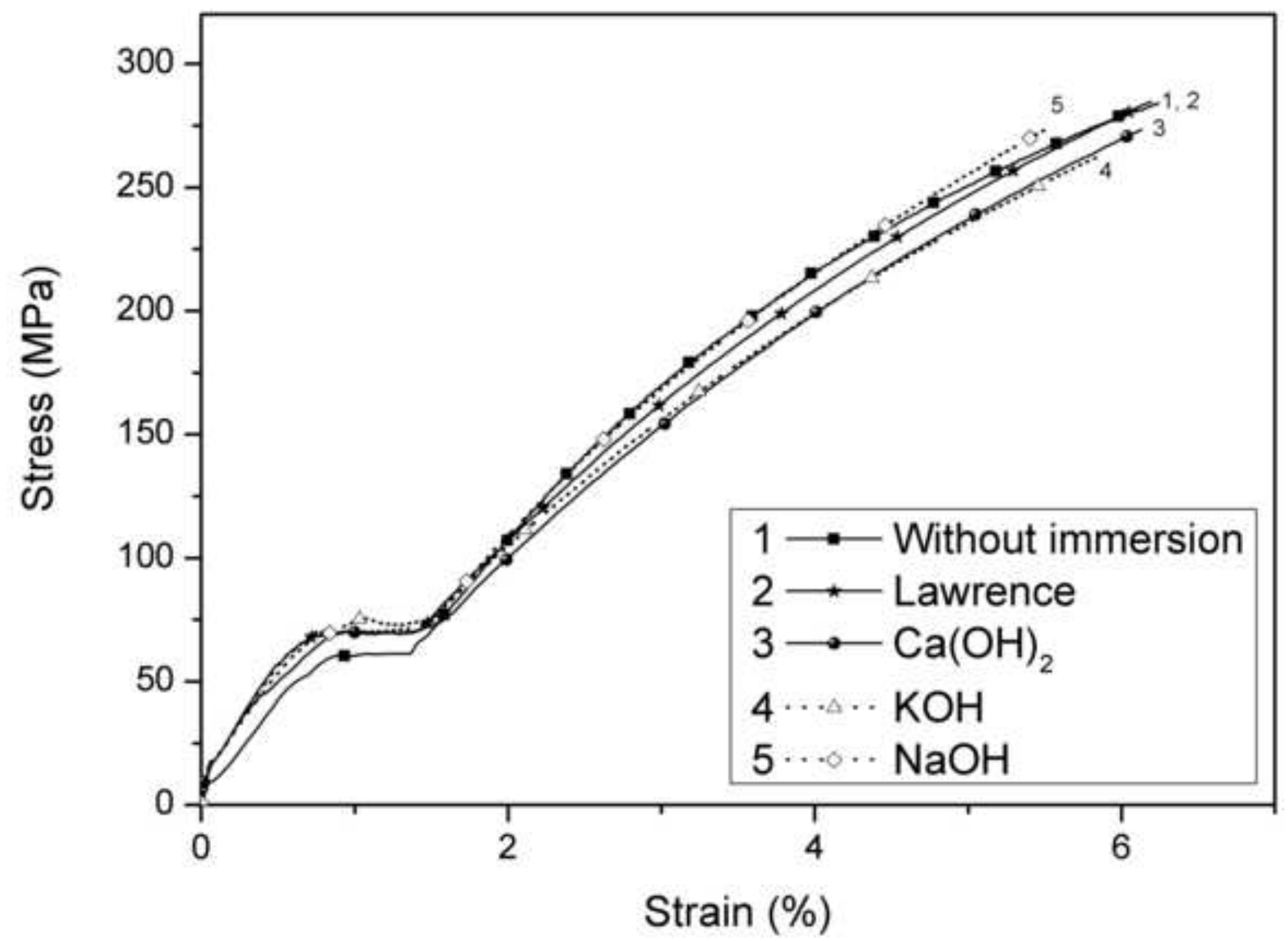




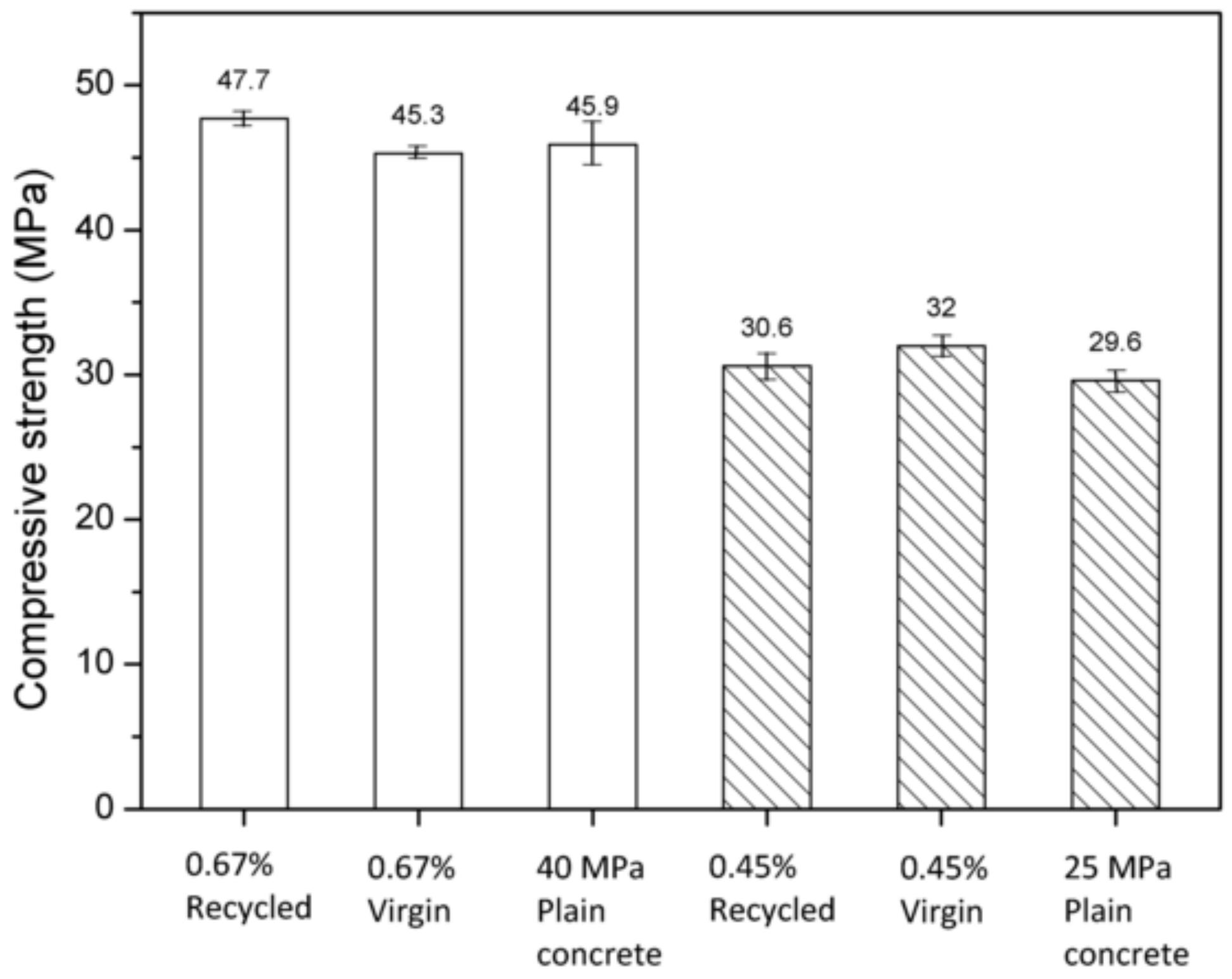


Click here to download high resolution image

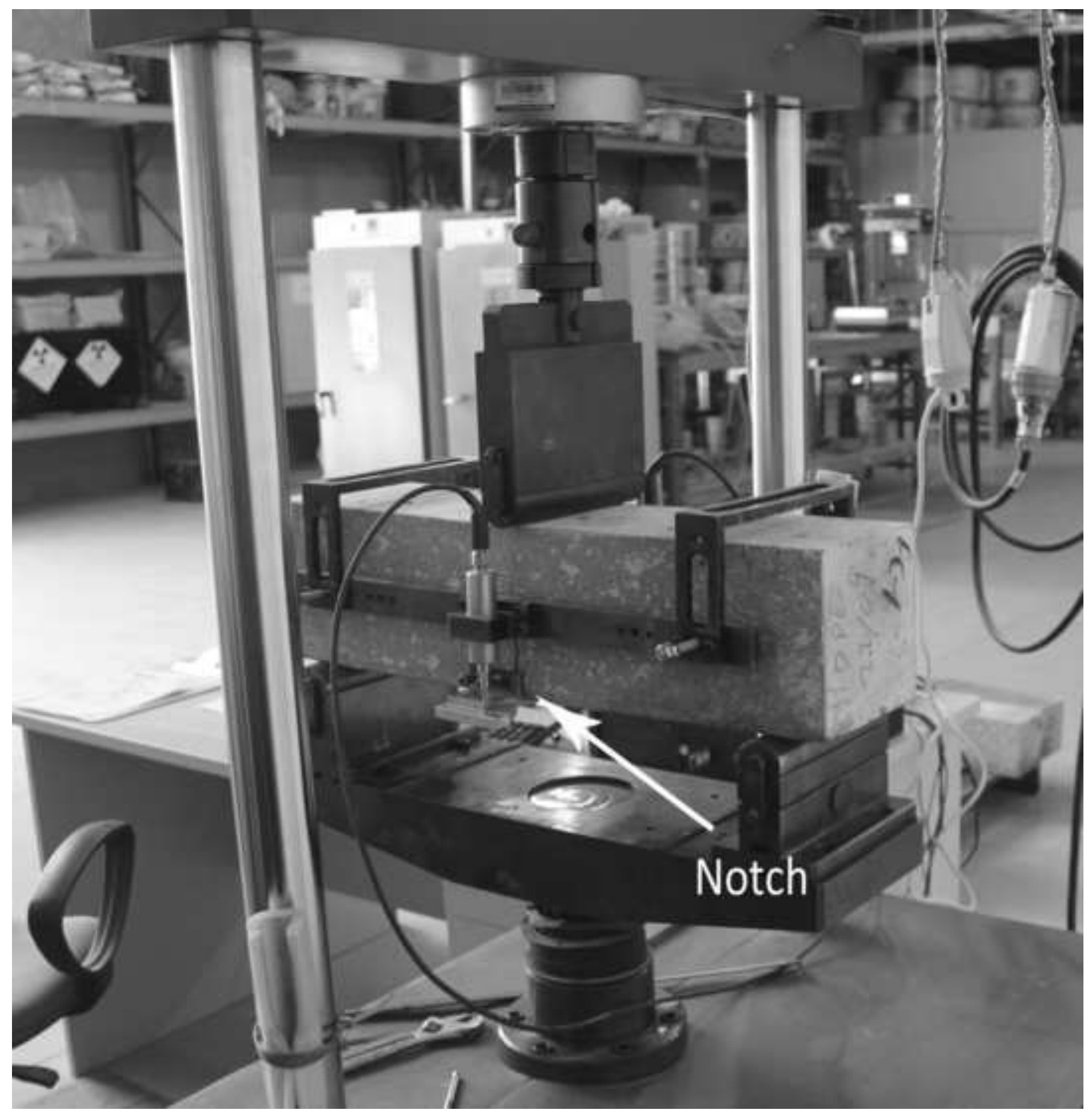


Click here to download high resolution image
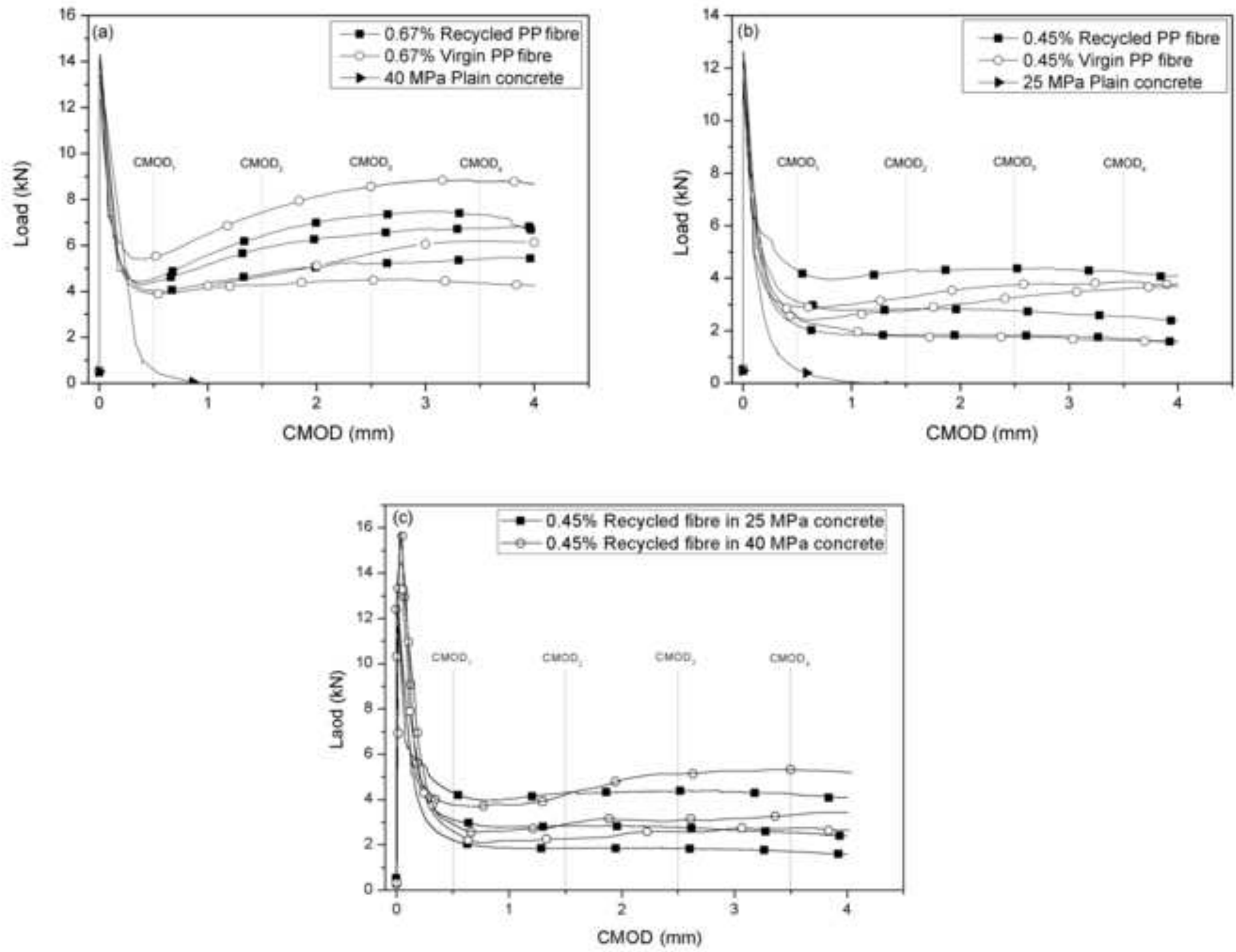

Figure 6

CMOD (mm)

$\mathrm{CMOD}(\mathrm{mm})$ 


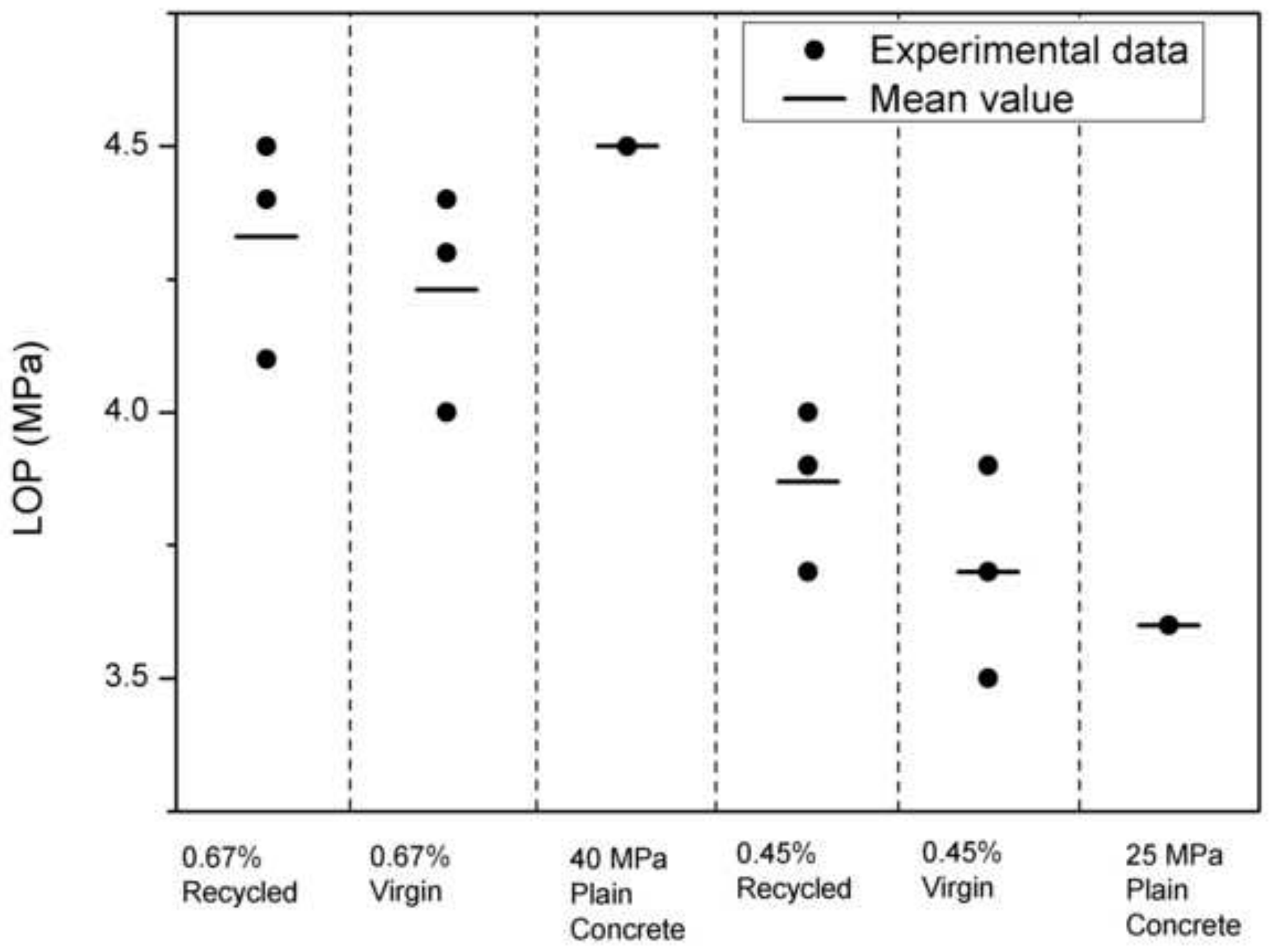




\section{Click here to download high resolution image}
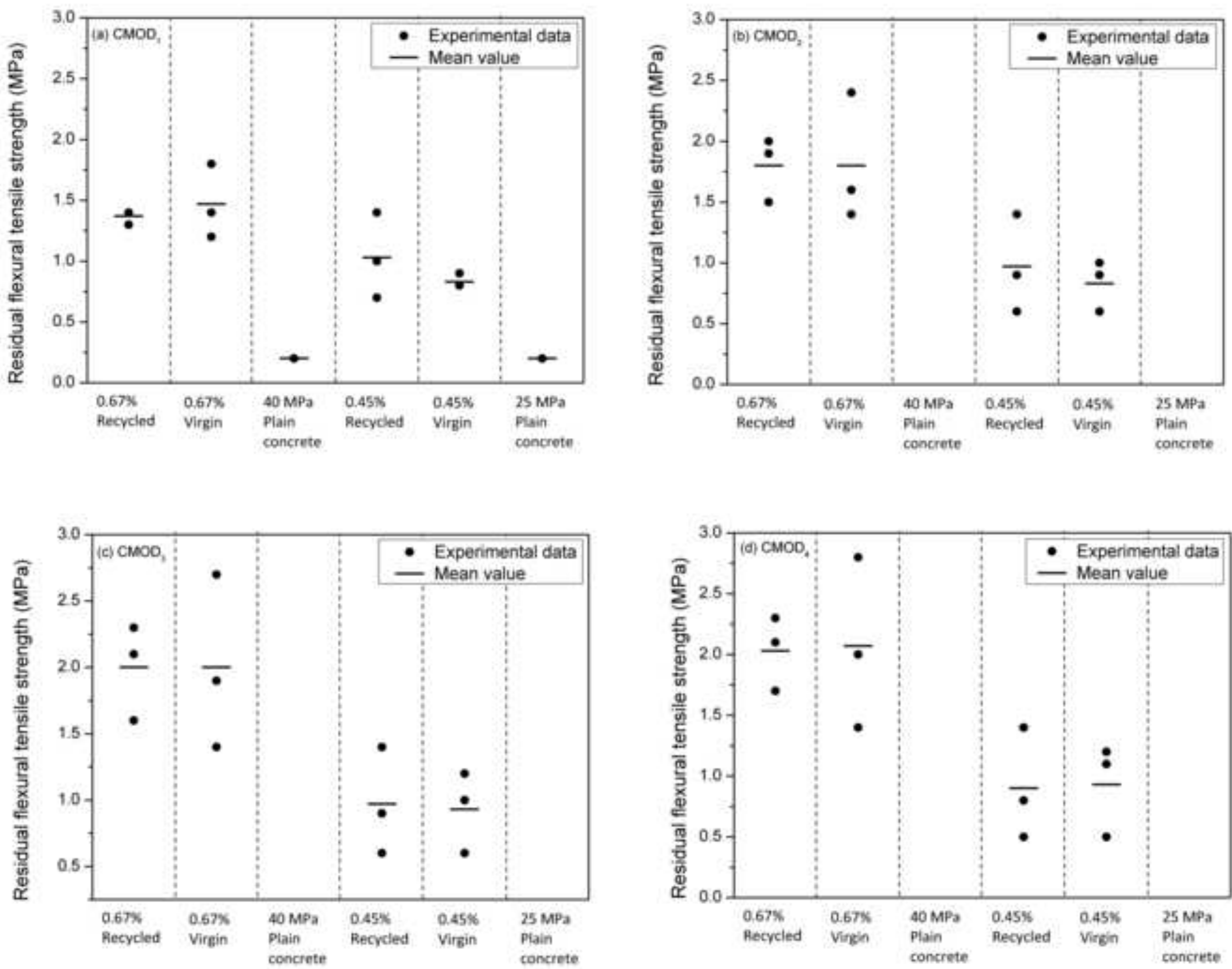

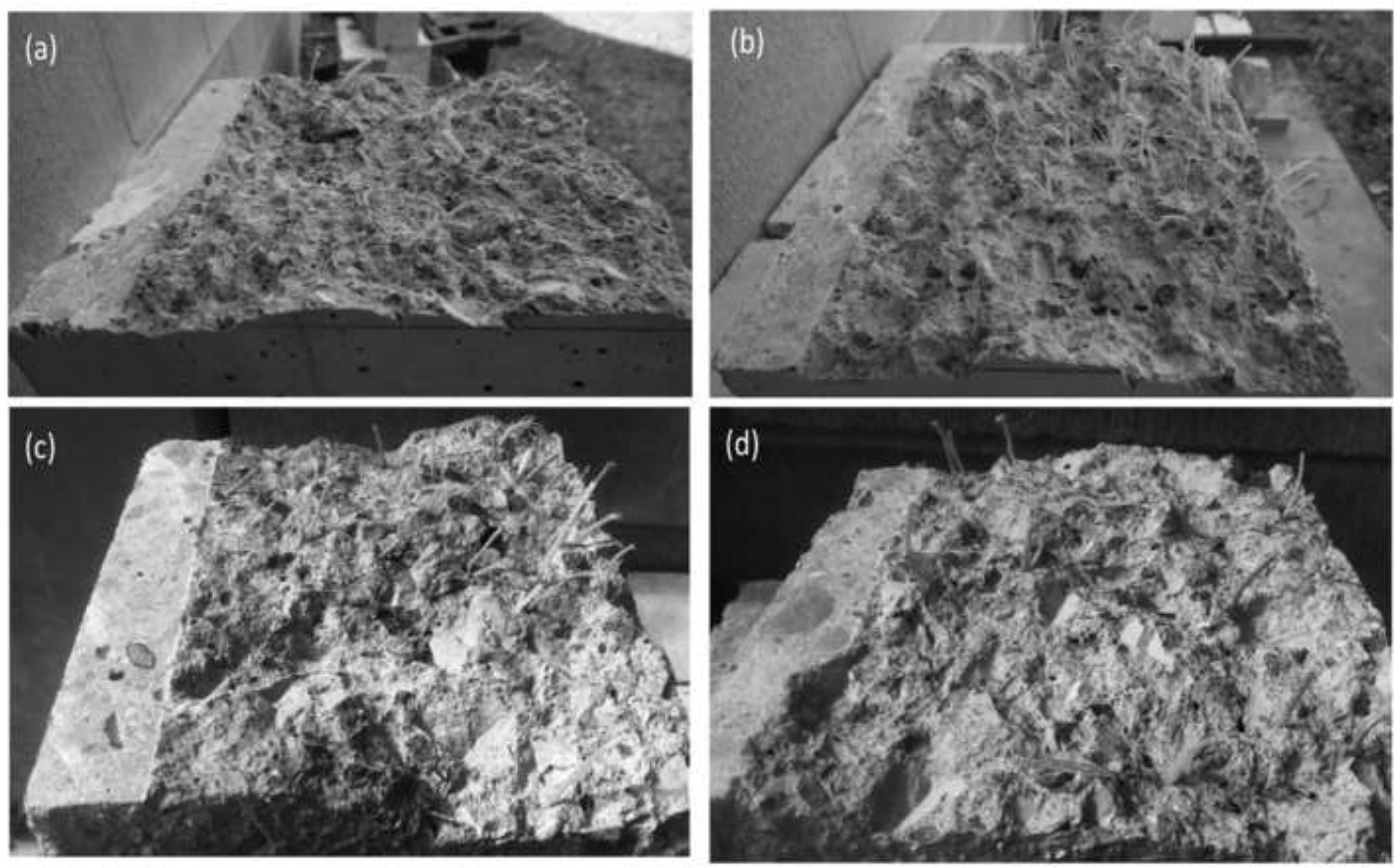
Click here to download high resolution image

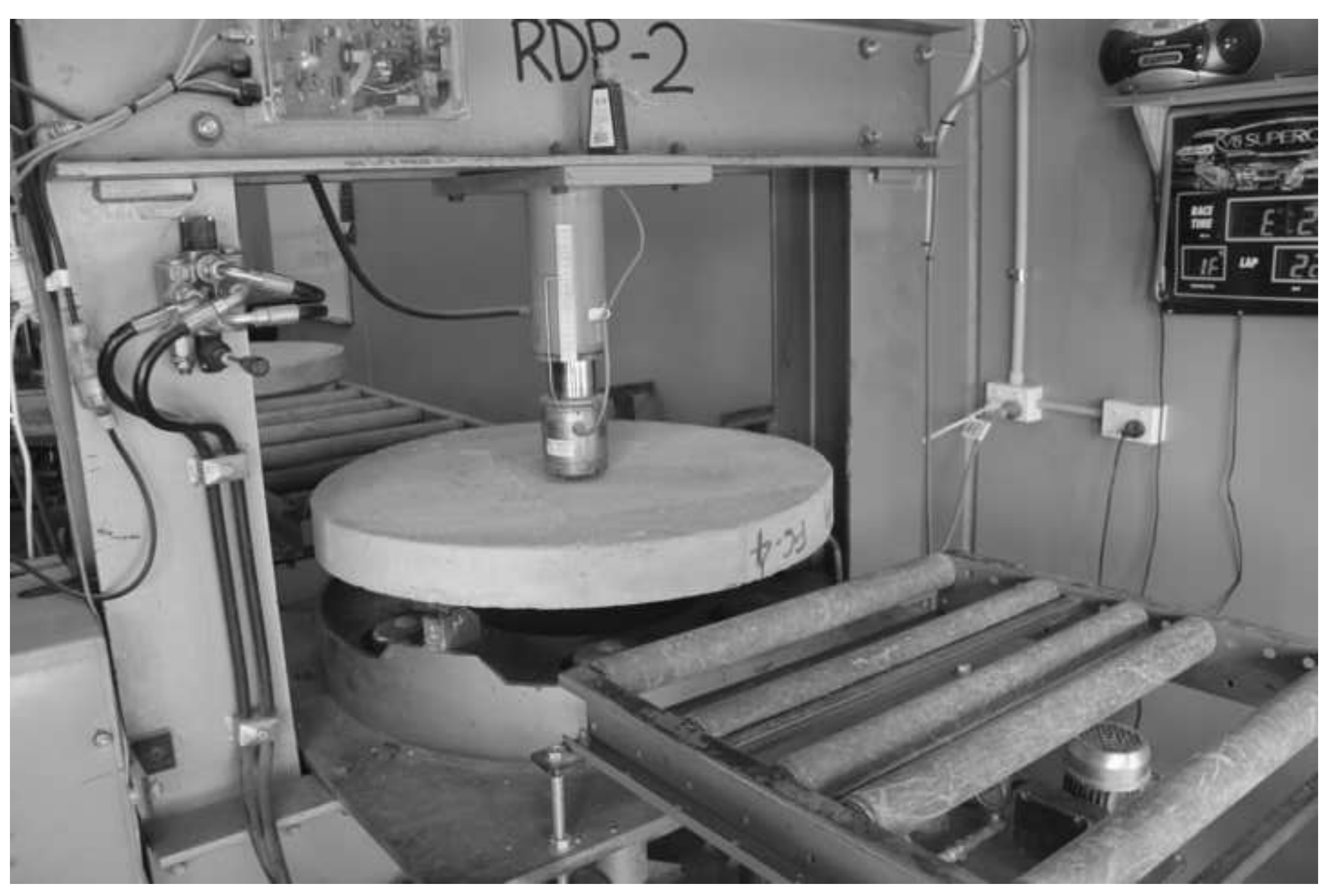

Clck here to download high resolution image 

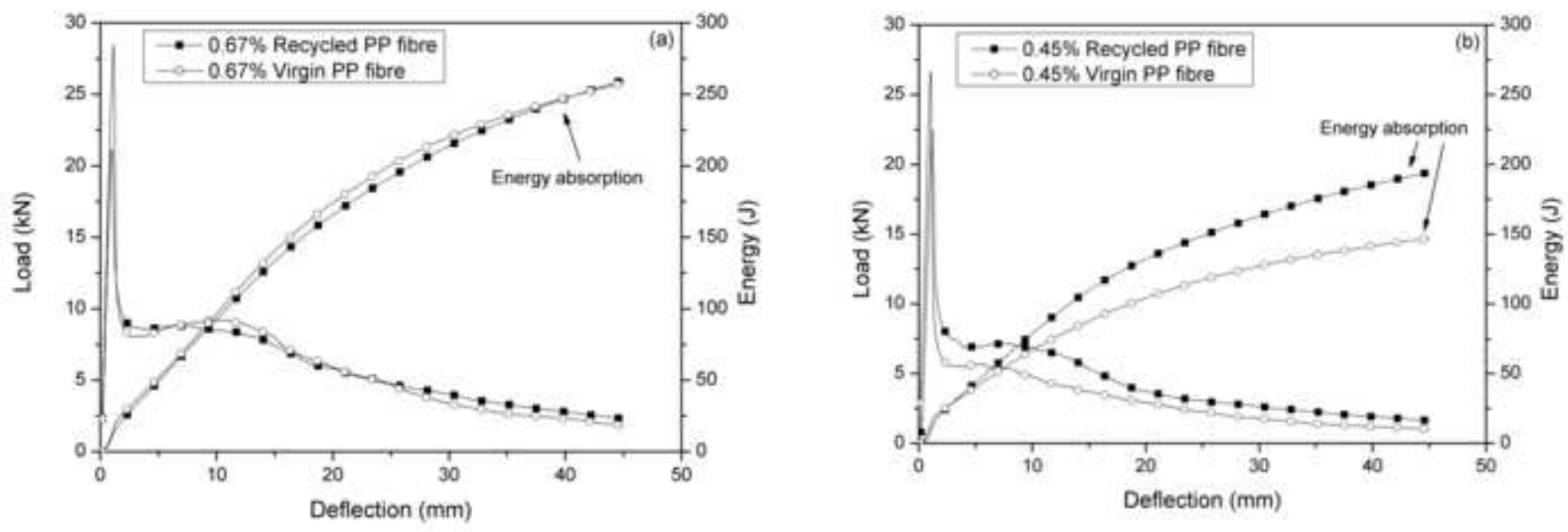